\title{
Desempenho e características da carcaça de novilhos terminados em pastejo rotacionado ou em confinamento
}

\author{
[Performance and carcass characteristics of steers finished in rotational grassing or feedlot] \\ D.O. Olmedo ${ }^{1,2}$, J.O.J. Barcellos ${ }^{2,5}$, L.C. Canellas ${ }^{2}$, M.M.S. Velho ${ }^{3}$, P. Paniagua ${ }^{1}$, \\ I. Horitá ${ }^{4}$, J.U. Tarouco ${ }^{2}$ \\ ${ }^{1}$ Faculdade Ciências Agrárias, UNA, Assunção, Paraguai \\ ${ }^{2}$ Programa de Pós-Graduação em Zootecnia - UFRGS \\ ${ }^{3}$ Aluno de graduação - UFRGS. Bolsista de IC/FAPERGS \\ ${ }^{4}$ Pesquisador CETAPAR - Alto Paraná, Paraguai \\ ${ }^{5}$ Bolsista de Produtividade - CNPq
}

\begin{abstract}
RESUMO
Foram avaliados o desempenho e as características de carcaça de 36 novilhos Brahman (Bh), Brangus (Bg) e Hereford adaptado (He), terminados em pastejo com suplementação (PSu) ou em confinamento (Conf). Os animais foram abatidos quando apresentavam espessura de gordura maior do que $4 \mathrm{~mm}$. Na dieta do Conf, a relação volumoso:concentrado foi de 60:40 (com base na matéria seca), continha 13\% de proteína bruta (PB) e 62\% de nutrientes digestíveis totais (NDT). O capim-mombaça continha, em média, 7\% de PB e 54\% de NDT, e o suplemento $24 \%$ de $\mathrm{PB}$ e $76 \%$ de NDT. Foi observada diferença $(\mathrm{P}<0,05)$ no sistema de terminação para 0 ganho de peso médio diário, com 1,200kg/cab/dia para Conf e 0,675kg/cab/dia para Psu. Os novilhos Bh e Bg pesaram, em média, 445,8kg, e o rendimento da carcaça quente foi de 58,4\%, valores maiores que os $399,1 \mathrm{~kg}$ e $55,4 \%$ obtidos pelos animais He. A área de olho de Longissimus foi maior para os animais Bg, 76,42 $\mathrm{cm}^{2}$. A maciez, 3,71 vs 4,89, e a espessura de gordura subcutânea, 4,64 vs 3,39, foram melhores nos animais terminados em Conf do que nos animais em Psu, respectivamente.
\end{abstract}

Palavras-chave: bovino de corte, cortes, dianteiro, traseiro, ganho de peso, maciez

\begin{abstract}
The productive performance and carcass of the 36 Brahman (Bh), Brangus (Bg) and adapted Hereford (He) steers finished on feedlot (FD) or on rotational grazing with supplementation system (GS) were evaluated. The animals were slaughtered when the subcutaneous fat thickness was over $4 \mathrm{~mm}$. The feedlot diet had a forage: concentrate of 60:40 (in dry matter) 13\% crude protein (CP), 62\% of NDT. The mombaça gras CP level was $7 \%$ and $54 \%$ of NDT. The supplement had supplied $24 \%$ of CP and 76\% of NDT. A significant difference was observed for the average daily gain, being 1,200kg/head/day for FD steers and $0.675 \mathrm{~kg} / \mathrm{head} /$ day for GS steers. The effect of breed on slaughter weight was observed, being $445.8 \mathrm{~kg}$ for Bh and $\mathrm{Bg}$ and $399.19 \mathrm{~kg}$ for $\mathrm{He}$. The hot dressing percentage was higher for Bh and $\mathrm{Bg}$ than for $\mathrm{He}, 58.4 \%$ vs $55.4 \%$. The rib eye area was higher for $\mathrm{Bg}, 76.42 \mathrm{~cm}^{2}$ and tenderness measured by the shear force was lower for FD steers, at 3.71 than for GS steers, at 4.89. The subcutaneous fat thickness was higher for FD steers, at 4.64 than for GS steers, at $3.39 \mathrm{~mm}$.
\end{abstract}

Keywords: cut, hindquarter, weight gain, ternderness, forequarter

\section{INTRODUÇÃO}

A pecuária de corte da Améria do Sul enfrentou períodos de baixas lucratividades. Atualmente, passa por um processo de evolução, focada em aumentar o lucro sem elevar em demasia os custos de produção. Nesse sentido, a melhora dos índices zootécnicos é primordial para a

Recebido em 28 de setembro de 2009

Aceito em 4 de abril de 2011

E-mail: julio.barcellos@ufrgs.br

Trabalho de pesquisa financiado pelo Centro Tecnológico

Agropecuário del Paraguai - CETAPAR 
lucratividade da pecuária de corte, sendo que as atividades produtivas devem ser entendidas e manejadas dentro de um enfoque sistêmico, em busca da maximização da eficiência econômica (Barbosa et al., 2010).

Maiores lucros podem ser obtidos por meio da intensificação dos sistemas pecuários, o que depende da utilização racional dos recursos disponíveis e do investimento em insumos, principalmente alimentação (Restle e Vaz, 2003). Tecnologias como o confinamento e a suplementação alimentar no pasto são alternativas para a produção de animais precoces, que permitem alcançar maiores índices de produtividade e rentabilidade (Beretta et al., 2002).

Atualmente existe um crescente interesse mundial para definir e caracterizar a qualidade da carne produzida nos diferentes sistemas produtivos. Por esse motivo, a pesquisa deve manter o enfoque na geração de alternativas para que o produtor reduza a idade de abate e melhore a conversão alimentar, buscando produzir animais que proporcionem carne de qualidade, que atenda ao mercado consumidor.

Os parâmetros de qualidade de carne, do ponto de vista do produtor, estão mais associados a parâmetros de rendimento da carcaça, pois estes estão associados ao resultado econômico. Do lado do consumidor, que demanda qualidade, há procura por parâmetros determinados pela composição química e características sensoriais. O sistema produtivo, o biotipo animal, a nutrição e o manejo pré e pós-abate poderão modificar as características de carcaça dos animais (Santini et al., 2003). Ao trabalharem com novilhos para abate precoce, Menezes et al. (2005) relataram diferenças relevantes nas características de carcaça e carne de novilhos terminados em pastagens ou em confinamento.

O objetivo deste experimento foi avaliar o desempenho produtivo e as características da carcaça de bovinos das raças Brahman, Brangus e Hereford adaptado, terminados em dois sistemas produtivos, pastejo com suplementação (PSu) e em confinamento (Conf).

\section{MATERIAL E MÉTODOS}

O experimento foi realizado no Centro Tecnológico Agropecuário do Paraguai, situado no Departamento de Alto Paraná, Paraguai, no município de Yguaçu. O trabalho, desenvolvido de junho a setembro de 2007, consistiu no emprego de 36 novilhos com média de idade de 22 meses e média de peso inicial de 395kg. Os animais, das raças Hereford adaptado (He), Brahman (Bh) e Brangus (Bg), foram identificados, pesados e distribuídos de forma homogênea nos dois sistemas de terminação: Psu e Conf. As pesagens foram feitas a cada 28 dias após jejum de 16 horas.

Dezoito animais - seis de cada raça - foram terminados no Psu utilizando pastejo rotacionado em capim-mombaça, com intervalos fixos entre pastejos de 32 dias e quatro dias de utilização. $\mathrm{O}$ suplemento fornecido foi composto de milho (30\%), subproduto da limpeza de silo de soja $(69,5 \%)$ e sal mineral $(0,5 \%)$, oferecido na proporção de $1 \%$ do peso corporal. O teor médio de proteína bruta (PB) do concentrado foi de $27 \%$, e o de nutrientes digestíveis totais (NDT) $70 \%$, enquanto o capim-mombaça apresentou $7 \%$ de PB e $56 \%$ de NDT.

Os 18 animais do Conf foram mantidos em boxes cobertos e piso pavimentado, com área de $6 \mathrm{~m}^{2}$ por animal, alimentados à vontade, duas vezes ao dia. A dieta, calculada segundo o NRC (Nutrient..., 1996), propunha ganho de peso médio diário de $1,100 \mathrm{~kg} / \mathrm{animal}$, estimando-se o consumo de $2,5 \mathrm{~kg}$ de $\mathrm{MS} / 100 \mathrm{~kg}$ de peso corporal. Foi utilizada a relação volumoso: concentrado de 60:40 (base na MS), com uma dieta contendo $12 \%$ de PB e $64 \%$ de NDT. Os ingredientes e suas composições percentuais na dieta com base na MS foram: silagem de milho (50\%), milho grão (10\%), subproduto de silo de soja (30\%), feno de capim-mombaça $(9,5 \%)$, sal mineral $(0,5 \%)$.

A cada pesagem foi avaliada a espessura de gordura subcutânea (EG), por meio da ultrassonografia, na região da $12^{\mathrm{a}}$ e $13^{\mathrm{a}}$ costelas. Os animais que apresentaram EG $>4 \mathrm{~mm}$ foram selecionados para o abate. Foi realizada pesagem às $17 \mathrm{~h}$, antes de os novilhos serem levados ao abatedouro, sem jejum, correspondendo ao peso de saída (Psa). Foram transportados a um frigorífico comercial a $300 \mathrm{~km}$ do local do 
experimento e abatidos no dia seguinte, após a pesagem. As carcaças foram identificadas, lavadas, pesadas e resfriadas a $-2^{\circ} \mathrm{C}$ por $24 \mathrm{~h}$, sendo novamente pesadas, e, por meio de cálculos, obtiveram-se os rendimentos de carcaça quente e fria.

No lado direito da carcaça, foram realizadas as medidas de desenvolvimento, incluindo o comprimento de carcaça e o índice de compacidade da carcaça. Também realizou-se um corte transversal entre a $12^{\mathrm{a}}$ e $13^{\mathrm{a}}$ costelas, para exposição do músculo Longissimus (lombo). O seu contorno foi traçado em papel vegetal, e sua área foi obtida pelo sistema de digitalização de pontos. Esta área de músculo foi dividida pelo peso da carcaça para obtenção da área de Longissimus por $100 \mathrm{~kg}$ de carcaça. A EG foi obtida com auxílio de régua milimétrica, no mesmo local do músculo seccionado, a partir da média de três medidas (Muller, 1987).

No lado esquerdo da carcaça, foram feitos os cortes comerciais - traseiro, dianteiro e costilhar -, cujos respectivos pesos foram convertidos em porcentagens do peso de carcaça fria. A determinação do $\mathrm{pH}$ do lombo foi realizada $24 \mathrm{~h}$ após a sangria, utilizando-se $\mathrm{pH}$ digital. A determinação da força de cisalhamento (FC), utilizada como parâmetro para avaliar maciez, foi realizada por meio do texturômetro.

O delineamento estatístico foi inteiramente ao acaso, com arranjo fatorial de 3x2 (três grupos genéticos e dois sistemas de terminação). Cada tratamento foi composto de seis repetições, em que cada animal constituiu uma unidade experimental. O modelo matemático adotado na análise de variância foi:

$\mathrm{Y}_{\mathrm{ijk}}=\mu+\mathrm{GG}_{\mathrm{i}}+\mathrm{SI}_{\mathrm{j}}+(\mathrm{GGSI}) \mathrm{ij}+\epsilon_{\mathrm{ijk}}$, em que:

$\mathrm{Y}_{\mathrm{ijk}}=$ observação da variável dependente correspondente à raça $\mathrm{i}$, sistema de terminação $\mathrm{j}$ e repetição $\mathrm{k} ; \mu=$ média geral de todas as observações; $\mathrm{GG}_{\mathrm{i}}=$ efeito da i-ésima raça, sendo 1=Bh, 2=Br e 3=He, $\mathrm{SI}_{\mathrm{j}}=$ efeito do j-ésimo sistema de terminação, sendo 1=Psu e 2=Conf; (GGSI) ij= interação entre a raça de ordem i e o sistema de terminação de ordem $\mathrm{j} ; \epsilon_{\mathrm{ijk}}=$ erro experimental referente à observação da raça i, sistema de terminação j e repetição k.

Os dados foram analisados utilizando-se o procedimento GLM do pacote estatístico SAS ${ }^{\circledR}$, versão 8.0 para Windows ${ }^{\circledR}$ (SAS, 1999). Em um primeiro momento, foram empregados os pesos iniciais como covariáveis. Como não se obtiveram resultados, significativos, foram retirados do modelo. A comparação de médias foi realizada pelo teste Tukey ajustado, adotando-se o nível de significância de 5\%.

\section{RESULTADOS E DISCUSSÃO}

Não houve interação significativa de raças versus sistemas de terminação para as características estudadas. As variações encontradas nos pesos iniciais para animais terminados em PSu e Conf (Tab. 1) foram decorrentes do sistema de recria empregado e das diferenças genéticas inerentes às raças avaliadas. $\mathrm{O}$ peso inicial dos animais em Conf foi $11 \%$ menor do que o obtido pelos animais terminados em PSu.

Tabela 1. Médias para peso inicial, peso final, ganho médio diário e período de acabamento de acordo com a raça e o sistema de terminação

\begin{tabular}{llllll}
\hline & Trat & Brahman & Hereford & Brangus & Média \\
\hline Peso inicial, kg & PSu & 458,33 & 370,50 & 427,17 & $418,67 \mathrm{a}$ \\
& Conf & 391,67 & 341,50 & 381,00 & $371,40 \mathrm{~b}$ \\
& Média & $425,00 \mathrm{~A}$ & $356,00 \mathrm{~B}$ & $404,88 \mathrm{~A}$ & \\
\hline Peso final, kg & PSu & 501,33 & 420,50 & 486,67 & $469,50 \mathrm{a}$ \\
& Conf & 469,33 & 433,50 & 458,50 & $453,78 \mathrm{~b}$ \\
& Média & $485,33 \mathrm{~A}$ & $427,50 \mathrm{~B}$ & $472,58 \mathrm{~A}$ & \\
\hline Ganho médio diário, kg & PSu & 0,640 & 0,690 & 0,735 & $0,675 \mathrm{~b}$ \\
& Conf & 1,170 & 1,240 & 1,190 & $1,200 \mathrm{a}$ \\
& Média & 0,885 & 0,965 & 0,960 & \\
\hline Período de acabamento, dias & PSu & 70 & 70 & 79 & 73 \\
& Conf & 65 & 75 & 65 & 68 \\
& Média & 68 & 72 & 72 & \\
\hline
\end{tabular}

Médias seguidas por letras distintas, minúsculas na coluna ou maiúsculas na linha, para a mesma característica, diferem $(\mathrm{P}<0,05)$ entre si pelos testes t e Tukey, respectivamente. 
O emprego estratégico do sistema de terminação em Conf foi o de obter animais com pesos finais similares, e isso foi parcialmente obtido, pois os pesos finais foram 3,3\% menores do que os obtidos por animais terminados em PSu. Essa estratégia permite diminuir os lotes piores e melhorar a margem do negócio, mediante a uniformização dos animais destinados à venda.

Maiores ganhos médios diários (GMD) ocorreram entre os animais terminados em Conf em relação aos terminados em PSu (Tab. 1). Estas diferenças eram esperadas em decorrência das simulações feitas com o NRC (Nutrient..., 1996). Não foram verificadas diferenças no GMD entre as raças avaliadas.

Analisando-se os períodos de terminação das raças estudadas e os sistemas de terminação empregados, verifica-se que, para atingir grau de acabamento similar ( $>4 \mathrm{~mm}$ EG), foram necessários, em média, 70 dias para os dois sistemas. No momento do embarque, os novilhos $\mathrm{Bh}$ e $\mathrm{Bg}$ foram os mais pesados, e essa diferença manteve-se no peso de abate (Tab. 2). Não foram observadas diferenças no PSa para os dois sistemas de terminação. Para peso de abate, animais terminados em PSu foram 6\% mais pesados do que os confinados, isto é, houve diminuição das diferenças quanto aos pesos iniciais, que foram $11 \%$ maiores para os animais suplementados em relação aos Conf.

As perdas de peso no transporte e jejum prévio ao abate não diferiram entre as três raças avaliadas, mas foram 9,2\% maiores para os animais terminados em Conf. Por outro lado, os animais terminados em PSu tiveram 7,8\% de perdas. A velocidade de passagem de alimentos de maior concentração energética, assim como de alimentos moídos ou de menor tamanho de partícula, é maior do que a de alimentos grosseiros, que apresentam maior conteúdo de parede celular ou maior tamanho de partícula (Van Soest, 1994). Isto poderia ter sido a causa da maior perda de peso por transporte e jejum prévio ao abate entre os animais confinados.

Tabela 2. Médias para as características de pesos e de carcaças conforme a raça e o sistema de terminação

\begin{tabular}{|c|c|c|c|c|c|}
\hline & Trat & Brahman & Hereford & Brangus & Média \\
\hline \multirow[t]{3}{*}{ Peso de saída, kg } & PSu & 518,83 & 435,00 & 491,16 & 479,61 \\
\hline & Conf & 479,83 & 439,00 & 469,50 & 462,61 \\
\hline & Média & 499,33A & $437,00 \mathrm{~B}$ & $475,83 \mathrm{~A}$ & \\
\hline \multirow[t]{3}{*}{ Peso de abate, $\mathrm{kg}$} & PSu & 472,74 & 399,36 & 459,99 & $436,07 a$ \\
\hline & Conf & 433,30 & 399,02 & 417,19 & 409,30b \\
\hline & Média & $453,02 \mathrm{~A}$ & 399,19B & 438,59A & \\
\hline \multirow[t]{3}{*}{ Peso carcaça quente, kg } & PSu & 276,52 & 221,35 & 265,73 & 254,53 \\
\hline & Conf & 255,67 & 221,38 & 242,48 & 239,84 \\
\hline & Média & $266,09 A$ & $221,37 \mathrm{~B}$ & $254,11 \mathrm{~A}$ & \\
\hline \multirow[t]{3}{*}{ Rendimento carcaça quente, \% } & PSu & 58,17 & 55,50 & 58,83 & 57,17 \\
\hline & Conf & 59,00 & 55,30 & 58,53 & 57,72 \\
\hline & Média & $58,58 \mathrm{~A}$ & $55,41 \mathrm{~B}$ & $58,33 \mathrm{~A}$ & \\
\hline \multirow[t]{3}{*}{ Peso carcaça fria, kg } & $\mathrm{PSu}$ & 270,08 & 215,50 & 258,04 & $247,87 a$ \\
\hline & Conf & 249,24 & 214,03 & 239,39 & $234,22 b$ \\
\hline & Média & $259,66 \mathrm{~A}$ & $214,76 \mathrm{~B}$ & $248,72 \mathrm{~A}$ & \\
\hline \multirow[t]{3}{*}{ Quebra no resfriamento, \% } & $\mathrm{PSu}$ & 2,30 & 2,70 & 2,85 & 2,80 \\
\hline & Conf & 2,50 & 3,31 & 2,58 & 2,60 \\
\hline & Média & 2,40 & 3,00 & 2,70 & \\
\hline \multirow[t]{3}{*}{ Comprimento carcaça, cm } & $\mathrm{PSu}$ & 130,42 & 122,58 & 129,22 & 127,40 \\
\hline & Conf & 125,55 & 123,08 & 125,08 & 124,57 \\
\hline & Média & $127,98 \mathrm{~A}$ & $122,83 B$ & $127,15 \mathrm{~A}$ & \\
\hline \multirow{3}{*}{$\begin{array}{l}\text { Índice de compacidade carcaça, } \\
\mathrm{kg} / \mathrm{cm}^{2}\end{array}$} & $\mathrm{PSu}$ & 2,12 & 1,80 & 2,05 & 1,99 \\
\hline & Conf & 2,04 & 1,80 & 1,96 & 1,93 \\
\hline & Média & $2,07 \mathrm{~A}$ & $1,80 \mathrm{~B}$ & $2,01 \mathrm{~A}$ & \\
\hline
\end{tabular}

Médias seguidas por letras distintas, minúsculas na coluna ou maiúsculas na linha, para a mesma característica, diferem $(\mathrm{P}<0,05)$ entre si pelos testes t e Tukey, respectivamente. 
Os maiores pesos de carcaça quente (PCQ) foram para animais $\mathrm{Bh}$ e Bg. Quanto ao rendimento de carcaça quente (RCQ), todos apresentaram rendimentos considerados adequados para novilhos - 53 a 59\% -, segundo Jorge et al. (2003). Esta característica esteve relacionada com o grau de acabamento similar para as três raças nos dois sistemas avaliados. $\mathrm{O}$ RCQ foi menor para o He em relação ao Bh e ao Bg. O rendimento de carcaça é uma característica importante para o frigorífico, por expressar a musculosidade, e para o produtor, por constituir uma forma de comercialização. É influenciado pela raça, idade, tipo de dieta, sexo e toalete na linha de abate do frigorífico. Entretanto, é altamente influenciado pelo período de jejum pré-abate, tornando difícil a comparação com resultados de autores que utilizam períodos de jejum diferentes (Brondani et al., 2004).

As quebras ao resfriamento (QR) refletem a perda de peso que a carcaça sofre durante o processo de resfriamento nas primeiras 24 horas após o abate e, geralmente, são influenciadas pelo grau de acabamento da carcaça, em que a gordura atua como isolante térmico para evitar a desidratação. Muller (1987) verificou que carcaças com maior grau de acabamento apresentam menor perda durante o resfriamento. Não foram encontradas diferenças entre as raças avaliadas e os sistemas de terminação, pois todos os animais foram levados ao abate após a avaliação por ultrassom, com o intuito de garantir um grau mínimo de acabamento (>4,0mm EG).

O sistema de terminação não influenciou o comprimento da carcaça e o índice de compacidade da carcaça. Essas características estão relacionadas, principalmente, à raça e à idade do animal. A semelhança entre Bh e Bg para essas características pode ser explicada pela similaridade no peso de abate e nos pesos de carcaça quente e fria de ambos.

Quanto ao percentual de cortes comerciais (Tab. 3), constatou-se que o dianteiro, o serrote e o costilhar não apresentaram diferenças entre os sistemas de terminação, porém animais Bh apresentaram carcaças com maior porcentagem de dianteiro em relação aos He, 34,3\% vs 32,6\%. Pacheco et al. (2005) relataram que a deposição de gordura, não só de cobertura, mas também a intramuscular, pode alterar a participação dos cortes comerciais da carcaça, o que, neste estudo, não foi confirmado pela não correlação significativa entre percentual de costilhar e EG $(0,04 ; \mathrm{P}<0,05)$.

Tabela 3. Médias para percentual de dianteiro, costilhar e serrote da carcaça, peso absoluto e percentual dos cortes filé-mignon e semitendinosus, de acordo com a raça e o sistema de terminação

\begin{tabular}{llllll}
\hline & Trat & Brahman & Hereford & Brangus & Média \\
\hline Dianteiro, \% & PSu & 35,00 & 32,67 & 33,83 & 33,83 \\
& Conf & 33,67 & 32,50 & 32,33 & 32,83 \\
& Média & $34,33 \mathrm{~A}$ & $32,58 \mathrm{~B}$ & $33,08 \mathrm{AB}$ & \\
\hline Costilhar, \% & PSu & 16,58 & 18,83 & 17,83 & 17,74 \\
& Conf & 17,60 & 18,83 & 18,33 & 18,22 \\
& Média & $17,09 \mathrm{~B}$ & $18,83 \mathrm{~A}$ & $18,08 \mathrm{AB}$ & \\
\hline Serrote, \% & PSu & 48,67 & 48,67 & 48,67 & 48,67 \\
& Conf & 48,50 & 48,83 & 49,50 & 48,94 \\
& Média & 48,58 & 48,75 & 49,08 & \\
\hline Lagarto, \% & PSu & 0,97 & 0,84 & 0,90 & $0,91 \mathrm{a}$ \\
& Conf & 0,89 & 0,86 & 0,93 & $0,89 \mathrm{~b}$ \\
& Média & $0,93 \mathrm{~A}$ & $0,85 \mathrm{~B}$ & $0,92 \mathrm{~A}$ & \\
\hline Filé-mignon, \% & PSu & 0,84 & 0,87 & 0,84 & 0,88 \\
& Conf & 0,85 & 0,91 & 0,89 & 0,85 \\
\hline
\end{tabular}

Médias seguidas por letras distintas, minúsculas na coluna ou maiúsculas na linha, para a mesma característica, diferem $(\mathrm{P}<0,05)$ entre si pelos testes t e Tukey, respectivamente. 
Os valores médios dos cortes comerciais por $100 \mathrm{~kg}$ de carcaça do dianteiro e do costilhar foram mais baixos que os reportados por Pacheco et al. (2005) e mais altos que os encontrados por Vaz e Restle et al. (2001). O percentual de traseiro foi menor do que 0 reportado na literatura, que relata variabilidade de 50,5\% a 59,1\% (Menezes et al., 2005; Pacheco et al., 2005; Freitas et al., 2008).

O percentual de traseiro não apresentou diferenças entre as três raças avaliadas, nem entre os sistemas de terminação. Entre os cortes comerciais da carcaça, o traseiro tem os músculos de maior valor comercial. A predominância de sangue zebu no Bh e no Bg foi benéfica só para valores de dianteiro, similar aos dados encontrados por Pacheco et al. (2005), que observaram superioridade dos novilhos com maior predominância Nelore (43,7\%) em relação ao Charolês (42,6\%). Porém, Faturi et al. (2002) verificaram a similaridade no percentual dos diferentes cortes comerciais da carcaça entre novilhos mestiços filhos de touros Charolês ou de touros Nelore, semelhante aos dados já apresentados por Vaz (1990).
A área de olho de lombo (AOL) é uma característica que está associada à musculosidade da carcaça e, neste trabalho, foi influenciada pela raça (Tab. 4). Bg foi melhor, $76,42 \mathrm{~cm}^{2}$, em relação ao $\mathrm{He}, 69,41 \mathrm{~cm}^{2}$, e ao $\mathrm{Bh}, 69,33 \mathrm{~cm}^{2}$. Vários trabalhos têm demonstrado maiores AOL em bovinos cruzados, quando comparados ao Nelore (Huffman et al., 1990; Vaz e Restle, 2001). Moreira et al. (2003), ao compararem novilhos produtos de cruzamentos Bos indicus com Bos taurus e Nelore, observaram AOL de $71,8 \mathrm{~cm}^{2}$ e $66,4 \mathrm{~cm}^{2}$, respectivamente, resultados próximos aos encontrados no presente trabalho.

$\mathrm{O} \mathrm{Bg}$, que pode ser uma raça de maturidade mais tardia em relação ao He, apresentou maior AOL, aspecto não observado no Bh, raça que também apresenta maturidade tardia em relação ao He. No trabalho de Hilton et al. (2004), não foram observadas diferenças para esta característica quando avaliaram animais produtos de cruzamentos com $\mathrm{Bh}$ e raças britânicas. Entretanto, quando foi estudada a área do músculo Longissimus/100 kg de carcaça, o He, 32,3 e o Bg, 30,7 apresentaram maior área do que o $\mathrm{Bh}, 26,7$.

Tabela 4. Médias para área do músculo Longissimus dorsi, área longissimus dorsi/100kg de carcaça fria, espessura de gordura subcutânea, $\mathrm{pH}$ e força de cisalhamento de acordo com a raça e o sistema de terminação

\begin{tabular}{llllll} 
& Trat & Brahman & Hereford & Brangus & Média \\
\hline Área do Longissimus dorsi, & PSu & 71,00 & 67,50 & 82,83 & 73,78 \\
cm $^{2}$ & Conf & 67,67 & 71,33 & 70,00 & 69,67 \\
& Média & $69,33 \mathrm{~B}$ & $69,41 \mathrm{~B}$ & $76,42 \mathrm{~A}$ & \\
\hline Área do Longissimus/100kg & PSu & 26,29 & 31,32 & 32,09 & 29,14 \\
carcaça fria, cm ${ }^{2}$ & Conf & 27,15 & 33,33 & 29,29 & 29,22 \\
& Média & $26,70 \mathrm{~B}$ & $32,32 \mathrm{~A}$ & $30,72 \mathrm{~A}$ & \\
\hline Espessura de gordura & PSu & 3,83 & 3,17 & 3,17 & $3,39 \mathrm{~b}$ \\
subcutânea, mm & Conf & 4,00 & 4,50 & 5,41 & $4,64 \mathrm{a}$ \\
& Média & 3,92 & 3,83 & 4,29 & \\
\hline Ph & PSu & 5,80 & 5,79 & 5,64 & 5,74 \\
& Conf & 5,79 & 5,62 & 5,73 & 5,72 \\
\hline Força de cisalhamento, & Média & 5,79 & 5,70 & 5,69 & \\
kgf/cm & PSu & 4,01 & 4,95 & 5,70 & $4,89 a$ \\
& Conf & 3,33 & 4,13 & 3,70 & $3,71 b$ \\
\hline
\end{tabular}

Médias seguidas por letras distintas, minúsculas na coluna ou maiúsculas na linha, para a mesma característica, diferem $(\mathrm{P}<0,05)$ entre si pelos testes t e Tukey, respectivamente.

A espessura de gordura subcutânea, atributo importante de carcaça, situou-se acima de $3 \mathrm{~mm}$, medida que os frigoríficos consideram adequada.
Para EG não foram observadas diferenças entre as raças, porém verificou-se efeito do sistema de terminação sobre a espessura de gordura. Os 
animais terminados em Conf apresentaram melhor resultado que os terminados em PSu (Tab. 4). Um aspecto que deve ter contribuído para a maior deposição de EG nos animais terminados em Conf foi a densidade energética da dieta e o elevado GMD desses animais (Tab. 1). Uma vez atendidas as exigências de mantença, crescimento de órgãos e dos tecidos, o exedente de energia consumida é depositado sob a forma de gordura. Segundo o NRC (Nutrient..., 1996), a deposição de gordura nos animas depende do grupo genético, do peso corporal do animal, da intensidade de ganho de peso, da maturidade e da densidade energética da dieta.

Outros trabalhos têm mostrado resultados diferentes dos obtidos neste experimento. Crouse et al. (1989), Bidner et al. (2002) e Hilton et al. (2004) verificaram maior EG nos Bos taurus quando comparados aos Bos indicus. Uma possível explicação para este resultado poderia ser as diferentes curvas de crescimento dos tecidos, acumulando maior ou menor quantidade de gordura segundo a maturidade fisiológica dos animais (Di Marco et al., 2007).

Não foi verificado efeito do sistema de terminação e da raça sobre o pH da carcaça quente. Norman (1982) estabeleceu que o aumento do pH acima de 5,5 leva à diminuição da maciez e concluiu que a maior variação no pH final está fortemente associada ao estresse préabate. Luckett et al. (1975), ao analisarem as características de carcaça de novilhos das raças Brahman, Charolês, Angus e Hereford e seus cruzamentos, encontraram valores de $\mathrm{pH}$ da carcaça quente de 6,64 , valores mais altos do que os obtidos no presente trabalho.

Neste trabalho, não foi verificada relação entre o $\mathrm{pH}$ e a força de cisalhamento (FC) $(\mathrm{P}>0,05)$. Nos animais do Conf ocorreram valores mais baixos de FC do que nos do PSu (Tab. 4). Existe a tentativa de evidenciar que tanto a quantidade como a qualidade de colágeno possam ser modificadas pelo regime alimentar de animais em crescimento. Desse modo, espera-se que o crescimento rápido de animais favoreça a renovação do colágeno, aumentando, assim, a maciez (Lawrie, 2005).

Alguns trabalhos relataram que a maciez da carne é menor nas raças zebuínas (Norman, 1982; Crouse et al., 1989; Koohmaraie et al., 1994). De acordo com Thompson (2002), o maior percentual de sangue zebuíno resulta em menor escore de maciez quando comparado ao das raças taurinas. Marshal (1994) atribuiu a menor maciez em cortes de Bos indicus à maior atividade inibidora da calpastatina, uma protease cálcio dependente.

\section{CONCLUSÕES}

Animais das raças Brahman, Brangus e Hereford adaptado atingem desempenho produtivo semelhante em diferentes sistemas de terminação. A musculosidade na carcaça, representada pela área de olho de lombo, é maior em novilhos cruzados em relação a novilhos de raças puras. Animais alimentados com maior quantidade de energia ganham mais peso por unidade de tempo; com isso, depositam mais gordura e produzem carne mais macia. Assim, a variável mais importante para atingir a condição de abate é o sistema de terminação.

\section{REFERÊNCIAS BIBLIOGRÁFICAS}

BARBOSA, F.A.; GRAÇA, D.S.; ANDRADE, V.J. Produtividade e eficiência econômica de sistemas de produção de cria, recria e engorda de bovinos de corte na região sul do estado da Bahia. Arq. Bras. Med. Vet. Zootec., v.62, p.677-685, 2010.

BERETTA, V.; LOBATO, J.F.P.; MIELITZ NETTO, C.G. Produtividade e eficiência biológica de sistemas de recria e engorda de gado de corte no Rio Grande de Sul. Rev. Bras. Zootec., v.31, p.696-706, 2002.

BIDNER, T.D.; WYATT, W.E; HUMES, P.E. et al. Influence of Brahman-derivative breeds and Angus on carcass traits, physical composition and palatability. $J$. Anim. Sci., v.80, p. 2126-2133, 2002.

BRONDANI, I.L.; SAMPAIO, A.A.M.; RESTLE, J. et al. Aspectos quantitativos de carcaças de bovinos de diferentes raças, alimentados com diferentes níveis de energia. Rev. Bras. Zootec., v.33, p.978-988, 2004.

CROUSE, J.D.; CUNDIFF, L.V.; KOCH, R. M. et al. Comparisons of Bos indicus an Bos Taurus inheritance for carcass beef characteristics an meat palatability. $J$. Anim. Sci., v.67, p.2661-2668, 1989.

DI MARCO, O.N.; BARCELLOS, J.O.J.; COSTA, E.C. Crescimento de bovinos de corte. Porto Alegre: UFRGS, 2007. 276p.

FATURI, C.; RESTLE, J.; BRONDANI, I.L. et al. Características da carcaça e da carne de novilhos de diferentes grupos genéticos alimentados em confinamento com diferentes proporções de grão de aveia e grão de sorgo no concentrado. Rev. Bras. Zootec., v.31, p.2024-2035, 2002. 
FREITAS, A.K.; RESTLE, J.; PACHECO, P.S. et al. Características de carcaça de bovinos Nelore inteiros vs castrados em duas idades, terminados em confinamento. Rev. Bras. Zootec., v.37, p.1055-1062, 2008.

HILTON, G.G.; GENTRY, J.G.; ALLEN, D.M. et al. Utilization of beef from different cattle phenotypes to produce a garanteed tender beef product. J. Anim. Sci., v.82, p.1190-1194, 2004.

HUFFMAN, R.D.; WILLIANS, S.E.; HARGROVE, D. et al. Effect of percentage Brahman and Angus breedind age-season of feeding and slaughter en point on feedlot performance and carcass characteristics. $J$. Anim. Sci., v.68, p.2243-2252, 1990.

JORGE, A.M.; FONTES, R.C.; CERVIERI, R. Crecimento relativo e composição do ganho de tecidos da carcaça de zebuínos de quatro raças. Rev. Bras. Zootec., v.32, p.986-991, 2003.

KOOHMARAIE, M.; WHEELER, T.L.; SHACKELFORD, S.D. Beef tenderness: regulation and prediction. Nebrasca: US Meat Animal Research Center, Clay Center, 1994. 12p.

LAWRIE, R.A. Ciência da carne. 6.ed. Porto Alegre: Artmed, 2005. 384p.

LUCKETT, R.L.; BIDNER, T.D.; ICAZA, E.A. et al., Tenderness studies in straightbred and crossbred steers. J. Anim. Sci., v.40, p.470-473, 1975.

MARSHALL, D.M. Breed differences and genetic parameters for body composition traits in beef cattle. J. Anim. Sci., v.72, p.2745-2755, 1994.

MENEZES, L.F.; RESTLE, J.; BRONDANI, I.L. et al. Características da carcaça de novilhos de gerações avançadas do cruzamento alternado entre raças Charoles e Nelore, terminados em confinamento. Rev. Bras. Zootec., v.34, p.934-945, 2005.

MOREIRA, F.B.; DE SOUZA, N.E.; MATSUSHITA, $M$. et al. Evaluation of carcass characteristics and meat chemical composition of Bos indicus $x$ Bos Taurus crossbreed steers finished in pasture systems. Braz. Arch. Biol. Technol., v.46, p.609-616, 2003.
MULLER, L. Normas para avaliação de carcaças e concursos de carcaças de novilhos. 2. ed. Santa Maria: Universidade Federal de Santa Maria, 1987. 31p.

NUTRIENTS requeriments of dairy cattle. 6.ed. Washington DC: Academic, 1996. 158p.

NORMAN, G.A. Effect of breed and nutrition on the productive traits of beef cattlein south-east Brazil: part 3- meat quality. Meat Sci., v.6, p.79-96, 1982.

PACHECO, P.S.; RESTLE, J; da SILVA, J.H. et al. Desempenho de novilhos jovens e superjovens de diferentes grupos genéticos terminados em confinamento. Rev. Bras. Zootec., v.34, p.963-975, 2005.

RESTLE, J.; VAZ, F.N. Eficiência e qualidade na produção de carne bovina In: REUNIÃO ANUAL DA SOCIEDADE BRASILEIRA DE ZOOTECNIA, 40., 2003, Santa Maria. Anais...., Santa Maria: SBZ, 2003. CD-ROM.

SANTINI, F.J.; REARTE, D.; GRIGUERA, J.M. et al. Algunos aspectos sobre la calidad de carne bovina asociada a los sistemas de Producción. Unidade Integrada Balcarse, 2003. Disponível em: $<$ http://www.inta.gov.ar/balcarce/info/documentos/gan aderia/bovinos/nutrición/calidad de carnes. htm.>. Acessado em: 12/05/2009.

THOMPSON, J. Managing meat tenderness. Meat Sci., v.62, p.295-308, 2002.

VAN SOEST, P.J. Nutritional ecology of the ruminant. Ithaca, NY: Cornell University, 1994. 476p.

VAZ, F.N. Cruzamento alternado das raças Charoles e Nelore: características da carcaça de novilhos com diferentes idades confinados por dois invernos subsequente. In: REUNIÃO ANUAL DA SOCIEDADE BRASILEIRA DE ZOOTECNIA, 27., 1990, Campinas. Anais... Campinas: SBZ, 1990. 359p.

VAZ, F.N.; RESTLE, J. Efeito da raça e heterose para caracteristicas de carcaça de novilhos da primeira geração de cruzamentos entre Charoles e Nelore. Rev. Bras. Zootec., v.30, p.409-416, 2001. 